\title{
Curcumin: Synthesis optimization and in silico interaction with cyclin dependent kinase
}

\author{
MAHMOOD AHMED ${ }^{1}$ \\ MUHAMMAD ABDUL QADIR ${ }^{1}$ \\ MUHAMMAD IMTIAZ SHAFIQ ${ }^{2 *}$ \\ MUHAMMAD MUDDASSAR ${ }^{3}$ \\ ABDUL HAMEED ${ }^{4}$ \\ MUHAMMAD NADEEM ARSHAD ${ }^{5,6}$ \\ ABDULLAH M. ASIRI ${ }^{5,6}$ \\ ${ }^{1}$ Institute of Chemistry, University \\ of the Punjab, Lahore, Pakistan 54590 \\ ${ }^{2}$ Institute of Biochemistry and \\ Biotechnology, University of \\ the Punjab, Lahore, Pakistan 54590 \\ ${ }^{3}$ Department of Biosciences \\ COMSATS Institute of Information \\ Technology, Islamabad-Pakistan \\ ${ }^{4}$ H. E. J. Research Institute \\ of Chemistry, International Center \\ for Chemical and Biological Sciences \\ University of Karachi, Karachi-75270 \\ Pakistan \\ ${ }^{5}$ Chemistry Department, Faculty \\ of Science, King Abdulaziz University \\ Jeddah 21589, Saudi Arabia \\ ${ }^{6}$ Center of Excellence for Advanced \\ Materials Research (CEAMR), Faculty \\ of Science, King Abdulaziz University \\ Jeddah 21589, Saudi Arabia \\ Accepted April 4, 2017 \\ Published online May 9, 2017
}

\begin{abstract}
Curcumin is a natural product with enormous biological potential. In this study, curcumin synthesis was revisited using different reaction solvents, a catalyst ( $n$-butylamine) and a water scavenger $\left[(n-\mathrm{BuO})_{3} \mathrm{~B}\right]$, to develop the optimal procedure for its rapid acquisition. During synthesis, solvent choice was found to be an important parameter for better curcumin yield and high purity. In a typical reaction, acetyl acetone was treated with boron trioxide, followed by condensation with vanillin in the presence of tri- $n$-butyl borate as water scavenger and $n$-butylamine as catalyst at $80{ }^{\circ} \mathrm{C}$ in ethyl acetate to afford curcumin. Moreover, curcumin was also extracted from turmeric powder and spectroscopic properties such as IR, MS, ${ }^{1} \mathrm{H}$ NMR and ${ }^{13} \mathrm{C}$ NMR with synthetic curcumin were established to identify any impurity. The purity of synthetic and extracted curcumin was also checked by TLC and HPLC-DAD. To computationally assess its therapeutic potential against cyclin dependent kinases (CDKs), curcumin was docked in different isoforms of CDKs. It was observed that it did not dock at the active sites of CDK2 and CDK6. However, it could enter into weak interactions with CDK4 protein.
\end{abstract}

Keywords: curcumin synthesis, CDKs, molecular docking

Curcumin $(\mathrm{C})$ is a phenolic compound that is considered to be a bioactive component of turmeric. Since ancient times it has been an integral part of ancient herbal medicine. Nowadays, it is widely used in medicine and in diet supplements. Structurally, curcumin

\footnotetext{
*Correspondence; e-mail: imtiazshafiqm@yahoo.com
} 
exists in keto and enol tautomeric forms due to intra-molecular hydrogen bonding between keto carbonyl oxygen and an enolic hydrogen atom (1). Possible therapeutic potential of curcumin was revealed in the last decades. Different studies have explained its efficacy against various types of cancers such as chemo resistant colon cancer cells, esophageal cancers, thyroid carcinomas, skin cancer (2) and as a potent anti-inflammatory agent (3). Curcumin regulates various growth factors, protein kinases, inflammatory cytokines and transcription factors to suppress the metastases and proliferation of human tumors (4). Other than anticancer and antitumor activities, it has also shown its effects against a variety of diseases such as respiratory tract infection, hepatic steatosis, skin photoageing, Parkinson's disease, pathogenesis of obesity, diabetes, HIV-associated diarrhea and Alzheimer's disease, through inhibition of amyloid beta oligomer formation (5-8). The structure-activity relationship studies of curcumin molecule against different biological targets have indicated that the presence of two phenyl rings with a C-7 linker with ketoenol function ( $\mathrm{C}=\mathrm{O}$ groups as hydrogen acceptors and $\mathrm{C}-4$ as a hydrogen donor) are most important for its biological activities. However, unsaturation in the linker (conformational flexibility) is important for its antitumor/anticancer activity but not for redox regulatory or apoptotic activities (9). Synthetic methodology to produce curcumin from acetyl acetone and 4-hydroxy-3-methoxybenzaldehyde (vanillin) has been reported, but these methods require a long reaction time and give a typical low yield over 3-4 steps of the synthesis procedure (10). Therefore, a more efficient and concise method is needed to prepare curcumin in a short time.

Curcumin binds to different targets of cancer pathways, including protein kinases. It inhibits the activity of protein kinase $\mathrm{C}$ by forming hydrogen bonds with Leu 251 and Gln 257 (PKC) in the C1B subdomain. It also optimally fits within the binding pocket of glycogen synthase kinase-3b via attractive interactions with Val-135, Ile-62 and Arg-141 (11). Curcumin is also reported to be a non-comparative inhibitor of phosphorylase kinase. Different CDKs are known as cancer targets and some of them have an established role in the onset of cancer (12). CDK1, CDK2 and CDK4/CDK6 play an important role in regulation of the cell cycle. Any irregularity in the activities of these CDKs may lead to the development of cancer. To our best knowledge, there is no information about the binding of curcumin with CDKs. In order to study the binding of curcumin with CDK, molecular docking studies were carried out with the primarily aim of predicting if there are any interactions between curcumin and CDKs and, secondly, to get an idea for designing a curcumin-based novel derivative for its better interaction with CDKs.

\section{EXPERIMENTAL}

\section{Curcumin synthesis}

Curcumin synthesis was performed according to ref. 10 with slight modifications. Acetyl acetone $(1.03 \mathrm{~mL}, 10 \mathrm{mmol})$ and boric anhydride $(0.35 \mathrm{~g}, 5.0 \mathrm{mmol})$ were dissolved in ethyl acetate $(30 \mathrm{~mL})$, and vanillin $(3.04 \mathrm{~g}, 20 \mathrm{mmol})$ and tributyl borate $(10.8 \mathrm{~mL}, 40$ $\mathrm{mmol}$ ) were added. The reaction mixture was stirred at $80^{\circ} \mathrm{C}$ for $30 \mathrm{~min}$ and then $n$-butylamine $(0.4 \mathrm{~mL}, 5.0 \mathrm{mmol})$ in ethyl acetate $(5 \mathrm{~mL})$ was added dropwise over $30 \mathrm{~min}$ and the mixture was stirred for $4 \mathrm{~h}$ at $80^{\circ} \mathrm{C}$. The progress of the reaction was monitored by TLC analysis. Upon complete consumption of the starting material, hydrochloric acid ( $1 \mathrm{~mol}$ 


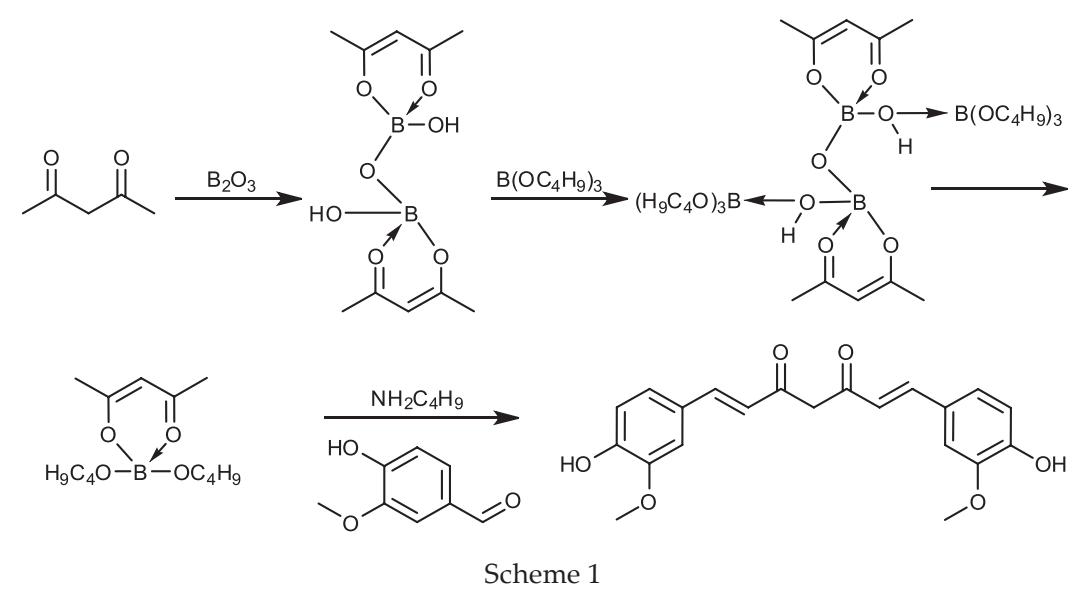

$\mathrm{L}^{-1}$ ) was added and the mixture was stirred. Organic layers of water-immiscible solvents were separated and extracted with an appropriate solvent. The combined organic layer was washed with water. The organic layer was dried over sodium sulfate, filtered and concentrated under reduced pressure. The crude product was recrystallized from methanol to give curcumin as a yellow solid. The synthesis route is given in Scheme 1.

\section{Extraction, isolation and purification of curcumin from turmeric}

Curcumin was extracted from turmeric powder along with other curcuminoids (demethoxycurcumin, DMC, and bis-demethoxycurcumin, BDMC) using $95 \%$ ethanol at room temperature. Finally, the curcuminoid mixture was precipitated with petroleum ether. Various solvent systems including dichloromethane, ethyl acetate, benzene, chloroform, toluene and methanol were used to identify curcuminoids in the mixture by thinlayer chromatography (TLC silica gel $60 \mathrm{~F}_{254}$, Merck, Germany).

Chloroform/methanol system was the best eluting agent to fractionate curcuminoids from the crude mixture using silica gel 60G column chromatography (Merck). First, elution with chloroform was carried out, and then polarity was increased by the chloroform/ methanol system to separate all fractions.

\section{Curcumin characterization}

In the present study, purity of synthesized and extracted curcumin was verified by the melting point, TLC, HPLC, IR, MS and NMR analyses. An Alpha IR spectrometer (FTIR-ATR, Bruker, USA) and NMR spectrometer (Bruker) were used to record the IR and ${ }^{1} \mathrm{H}$ NMR (500 MHz) and ${ }^{13} \mathrm{C}$ NMR $(125 \mathrm{MHz})$ spectra, respectively, while the melting point was measured with a Gallenkamp apparatus (Gallenkamp and Co, UK). NMR spectra were recorded in DMSO- $d_{6}$. A JEOL MS 600H-1 spectrometer (Jeol, Japan) with an electron spray ionization (ESI) interface was used for recording mass spectra.

HPLC Shimadzu Nexera X2 (Shimadzu, Japan) was equipped with a diode array detector and DGU-20A5 degasser (online), a variable volume loop injection valve and Phe- 
nomenex Luna $\mathrm{NH}_{2}$ column $(250 \mathrm{~mm} \times 4.6 \mathrm{~mm}, 5.0-\mu \mathrm{m}$ particle size $)$ and was used at 25 ${ }^{\circ} \mathrm{C}$. Mobile phase comprised ethanol/water $(85: 15, V / V)$, the flow was set at $1.0 \mathrm{~mL} \mathrm{~min}^{-1}$ and elution followed at $425 \mathrm{~nm}$. The Shimadzu LC program, LabSolutions analysis data system, was used for integration of peak areas.

All solutions were filtered through a $0.45-\mu \mathrm{m}$ nylon filter and sonicated before injection into the chromatographic system. The sonicator used was from Fischer Scientific, UK.

\section{Molecular docking and software}

Molecular docking studies provided an insight into optimal matching between proteins and other interacting molecules. Before carrying out molecular docking experiments, CDK2, CDK4 and CDK6 X-ray resolved crystal structures were downloaded from the protein data bank (www.rcsb.org). Hydrogen atoms were added and their co-crystal ligands were removed. The structures were also minimized to remove steric clashes. The curcumin for docking studies was sketched using the HyperChem 8.0 tool (13) and was minimized using the steepest descent algorithm. It was then docked in the crystal structure of CDK2 (PDB ID=2R3I), CDK4 (PDB ID=2W96) and CDK6 (PDB ID=1XO2) proteins using the GOLD docking software (14). The software was developed on the genetic algorithm and was trained for kinases and other related proteins. For docking simulations, the active site of CDKs was defined around the ATP binding site with a radius of $10 \AA$. The best docking pose of curcumin was selected based on the GOLD score. Different binding poses of the docked curcumin were analyzed using the PyMOL software.

\section{RESULTS AND DISCUSSION}

\section{Synthesis of curcumin}

Herein, the synthesis of curcumin from acetylacetone with vanillin under variable reaction conditions such as solvent systems, complexing agents, temperature, time, amount of water scavenger was studied in detail to afford an optimized yield. Moreover, curcumin was also extracted from turmeric to establish the purity of both extracted and synthetic curcumin samples.

Primary ingredients required for curcumin synthesis were acetyl acetone and 4-hydroxy-3-methoxybenzaldehyde (vanillin) in a theoretically stoichiometric ratio (1:2). In curcumin synthesis, the major issue such as Knoevenagel condensation at C-3 of acetyl acetone was prevented by the complexing agent boric oxide. Solvent selection was also regarded as an important factor to get appropriate solubility for the reactants, intermediates and products. Subsequently, the effective strength of the catalyst in basic media in different solvents to promote reaction was also an important parameter in curcumin synthesis. Various solvents including dimethylformamide (DMF), ethyl acetate (EtOAc), 1,4-dioxane, acetonitrile and toluene were employed (Table I). Effective basicity of a catalyst to deprotonate methyl groups of acetyl acetone in a suitable solvent is critical since a stronger base can deprotonate the phenolic $-\mathrm{OH}$ group, which results in deactivation of aromatic aldehyde (vanillin) required for the condensation reaction in curcumin synthesis. The base, $n$-butylamine, was found to be the most appropriate catalyst for the desired de- 
protonation of acetylacetone. Catalyst loading was performed slowly up to $40 \%$ of acetylacetone. During complex formation of diketone (acetylacetone) with the boron and formation of curcumin, water is produced. Water in reaction mixture reacts with the diketone complex and reduces the curcumin yield. Higher concentration of water in the reaction mixture hindered the chemical reaction, so anhydrous conditions were established using high purity solvents. The water scavenger tributyl borate was incorporated into the reaction to bind water produced during the chemical reaction and prevent its reaction with the diketone metal complex. The amount of water scavenger had a critical role in the reaction system. Different ratio of $(n-\mathrm{BuO})_{3} \mathrm{~B}$ to diketone was established.

Further, the overall reaction between the diketone complex (boron complex) and aldehyde (vanillin) was temperature dependent. Below $40{ }^{\circ} \mathrm{C}$, the rate of the reaction was slow and appropriate temperature conditions had to be maintained to get a workable yield. In this respect, we made efforts to optimize the reaction conditions for curcumin synthesis by varying the solvents with $n$-butylamine as catalyst and $(n-\mathrm{BuO})_{3} \mathrm{~B}$ as water scavenger at different temperatures (Table I). First, the reaction between acetyl acetone and vanillin (1:2 mole ratio) was carried out at $60{ }^{\circ} \mathrm{C}$ in DMF. The complexing agent $\left(\mathrm{B}_{2} \mathrm{O}_{3}\right)$ was added in a mole ratio to acetylacetone 1:1 without any water scavenger for a period of $12 \mathrm{~h}$. The yield obtained under the mentioned reaction conditions was very low $(6 \%)$, and then no significant improvement in yield was observed under the same reaction conditions with a water scavenger.

Afterwards, different solvents were utilized with different amounts of water scavenger $(n-\mathrm{BuO})_{3} \mathrm{~B}$, and catalyst $n$-butylamine, time and temperature. Ethyl acetate was found to be an excellent solvent for curcumin synthesis, with significant improvement in yield, which was due to better solubility of the reactants, intermediates and products. An increased amount of $(n-\mathrm{BuO})_{3} \mathrm{~B}$ improved the curcumin yield significantly. In the presence of acetonitrile and dioxane, almost identical yields were obtained. Using toluene as a solvent, either at 60 or $80^{\circ} \mathrm{C}$, only a small amount was observed. An excellent yield was obtained by using EtOAc at a temperature of $80{ }^{\circ} \mathrm{C}$ with $4: 1$ of $(n-\mathrm{BuO})_{3} \mathrm{~B}$ and 2:1 of $\mathrm{B}_{2} \mathrm{O}_{3}$ to acetylacetone (Table I).

Table I. Parameters of curcumin synthesis

\begin{tabular}{lcccc}
\hline Solvent & $\mathrm{H}_{2} \mathrm{O}$-scavenger & Temperature $\left({ }^{\circ} \mathrm{C}\right)$ & Time $(\mathrm{h})$ & Yield $(\%)$ \\
\hline DMF & None & 60 & 12 & 6 \\
DMF & $(n \text {-BuO })_{3} \mathrm{~B}$ & 80 & 12 & 15 \\
EtOAc & None & 60 & 4 & 21 \\
EtOAc & $(n-\mathrm{BuO})_{3} \mathrm{~B}$ & 60 & 4 & 43 \\
EtOAc & $(n-\mathrm{BuO})_{3} \mathrm{~B}$ & 80 & 4 & 89 \\
Dioxane & $(n-\mathrm{BuO})_{3} \mathrm{~B}$ & 60 & 12 & 20 \\
MeCN & $(n-\mathrm{BuO})_{3} \mathrm{~B}$ & 60 & 12 & 18 \\
Toluene & $(n-\mathrm{BuO})_{3} \mathrm{~B}$ & 60 & 12 & 3 \\
Toluene & $(n-\mathrm{BuO})_{3} \mathrm{~B}$ & 80 & 12 & 6 \\
\hline
\end{tabular}


Table II. Efficiency of different solvent systems for separation of curcuminoids by TLC

\begin{tabular}{lccc}
\hline \multirow{2}{*}{ TLC mobile phase } & \multicolumn{3}{c}{$R_{\mathrm{f}}$} \\
\cline { 2 - 4 } & Curcumin & $\begin{array}{c}\text { Demethoxy- } \\
\text { curcumin }\end{array}$ & $\begin{array}{c}\text { Bis-demethoxy- } \\
\text { curcumin }\end{array}$ \\
\hline Toluene/ethyl acetate (95:5) & 0.92 & 0.86 & 0.81 \\
Benzene/ethyl acetate (95:5) & 0.84 & 0.79 & 0.75 \\
Dichloromethane/methanol (95:5) & 0.54 & 0.46 & 0.35 \\
Chloroform/methanol (95:5) & 0.84 & 0.65 & 0.46 \\
\hline
\end{tabular}

\section{Extraction of curcumin}

A curcuminoid mixture $(\mathrm{C}, \mathrm{DMC}, \mathrm{BDMC})$ from turmeric powder was extracted and isolated after precipitation with petroleum ether and, then identified by TLC using various solvent systems (Table II). The chloroform/methanol solvent system both in TLC and the column was selected because excellent separations of all fractions were achieved at reasonable $R_{\mathrm{f}}$ values. All fractions of the curcuminoid mixture were then separated by column
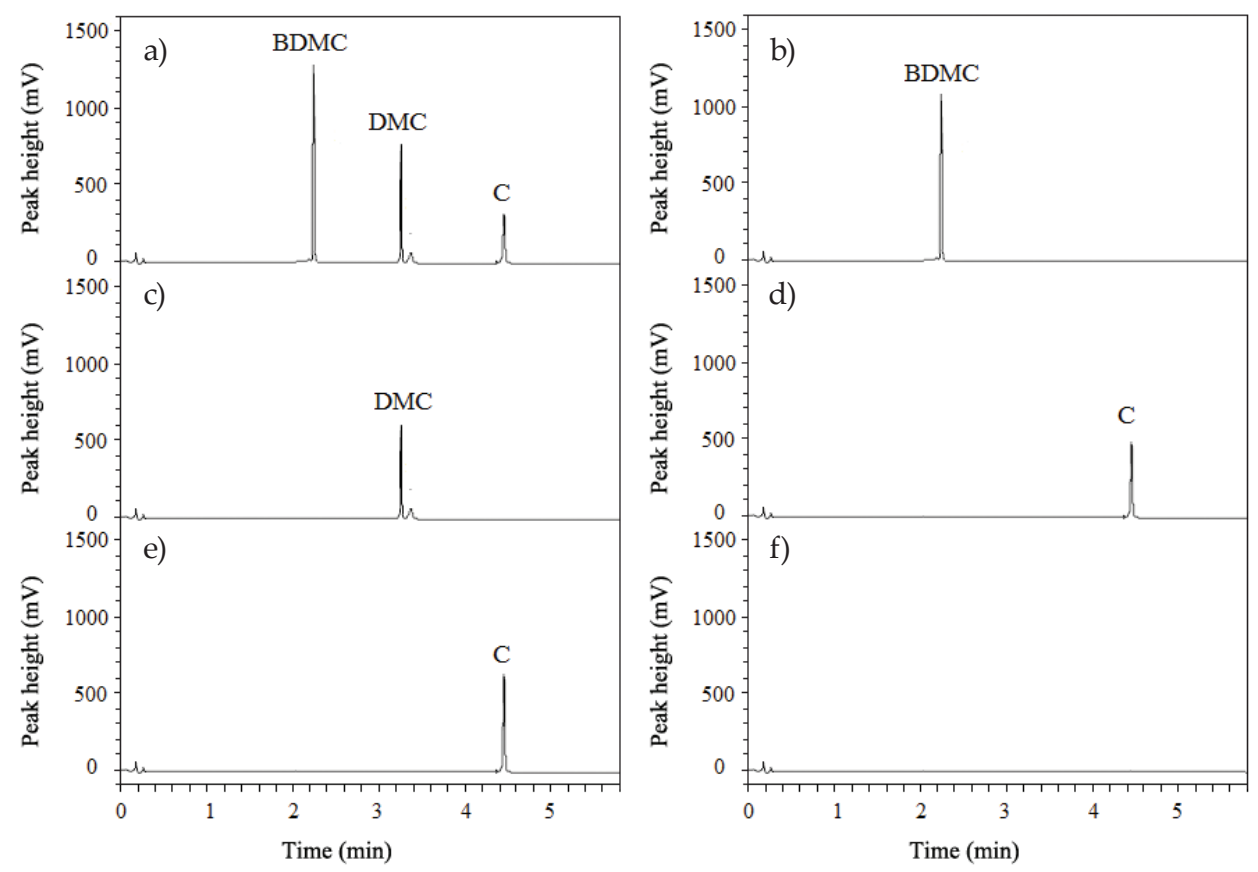

Fig. 1. Chromatograms obtained for: a) curcuminoids: bis-demethoxycurcumin (BDMC), demethoxycurcumin (DMC) and curcumin (C), b) bis-demethoxycurcumin (BDMC), c) demethoxycurcumin $(\mathrm{DMC}), \mathrm{d})$ extracted curcumin $(\mathrm{C})$, e) synthetic curcumin $(\mathrm{C})$ and f) mobile phase. 
<smiles>COc1cc(/C=C/C(=O)/C=C/c2ccc(/C=C/C(=O)CC(=O)/C=C/c3ccc(O)c(OC)c3)cc2OC)ccc1O</smiles>

Fig. 2. Keto-enol tautomerism of curcumin.

chromatography. TLC was performed for each separated fraction and a single spot was observed.

The curcuminoid mixture and each separated fraction were also confirmed by HPLC. Well resolved peaks of all three components at retention times of 2.28 (BDMC), 3.34 (DMC) and $4.42 \mathrm{~min}$ (C) were obtained, as shown in the chromatogram (Fig. 1). Synthetic curcumin was also analyzed by HPLC and a single well resolved peak confirmed excellent purity.

Curcumin separated from turmeric powder and synthetic curcumin were then subjected to the melting point, IR, MS and NMR analyses for purity confirmation. The melting point and IR vibration frequencies $\left(\mathrm{cm}^{-1}\right)$ are presented in Table III and there was no significant difference in the melting point and vibration frequencies of curcumin samples. Curcumin existed in the tautomeric form (keto and enol form, Fig. 2) and two peaks were obtained in the LC-MS system, peak 2 dominating. Peak 2 corresponded to the enol form due to a planar structure, which is more retentive on the ODS column surface than the folded structure of the keto form at position C-4 of pentadiene. Base peaks at $\mathrm{m} / \mathrm{z} 177.07$ and 177.08 (Fig. 3) were obtained for both synthetic and extracted curcumin, resp., and major peaks are presented in Table III. A computational approach determined that the enol form was more stable but this form does not influence the therapeutic properties of curcumin (15). ${ }^{1} \mathrm{H}$ NMR and ${ }^{13} \mathrm{C}$ NMR spectral data are given in Table IV. In ${ }^{1} \mathrm{H}$ NMR, a singlet with a chemical shift $(\delta)$ at 3.83 ppm corresponded to two methoxy groups and a sharp singlet

Table III. IR vibrational frequencies, major fragments of MS and melting points of curcumin

\begin{tabular}{|c|c|}
\hline Synthetic curcumin (m.p. $\left.=181-182{ }^{\circ} \mathrm{C}\right)$ & Extracted curcumin (m.p. $\left.=182-183^{\circ} \mathrm{C}\right)$ \\
\hline$v\left(\mathrm{~cm}^{-1}\right)$ & $v\left(\mathrm{~cm}^{-1}\right)$ \\
\hline $\begin{array}{l}\text { 3500.01, 2846.51, 1625.97, 1600.45, 1505.09, 1426.09, } \\
\text { 1274.41, 1230.46, 1202.11, 1151.08,1112.81,1026.33, } \\
\text { 983.82, 958.29, 884.57, 854.79, 806.67, 782.51, } \\
713.04\end{array}$ & $\begin{array}{l}\text { 3507.94, 2846.47, 1625.74, 1600.66, 1506.19, 1427.09, } \\
\text { 1274.71, 1231.76, 1202.71, 1151.18,1112.81,1026.04, } \\
\begin{array}{l}\text { 983.82, 960.39, 884.57, 854.79, 808.07, 782.51, } \\
713.04\end{array}\end{array}$ \\
\hline$m / z(\%)$ & $m / z(\%)$ \\
\hline $\begin{array}{l}51 \text { (7.5), } 77 \text { (12.2), } 89 \text { (16.1), } 91 \text { (10), } 117 \text { (15.7), } 131 \\
(17.4), 135 \text { (13.1), } 137(38.8), 145(32.3), 147(18.0), \\
149 \text { (12.4), } 150(28.3), 175(10.7), 177 \text { (100), } 190 \\
(41.4), 191(33.2), 217(15.6), 232(14.0), 272(15.7), \\
350 \text { (34.1), } 368(36.9)\end{array}$ & $\begin{array}{l}51 \text { (7.5), } 77 \text { (12.3), } 89 \text { (16.1), } 91(10), 117(15.8), 131 \\
(17.4), 135 \text { (13.1), } 137(38.8), 145(32.3), 147(18.0), \\
149 \text { (12.3), 150 (28.3), } 175 \text { (10.8), } 177 \text { (100), } 190 \\
(41.3), 191(33.2), 217 \text { (15.6), } 232(14.0), 272(15.7), \\
350 \text { (34.1), } 368(36.9)\end{array}$ \\
\hline
\end{tabular}


a)
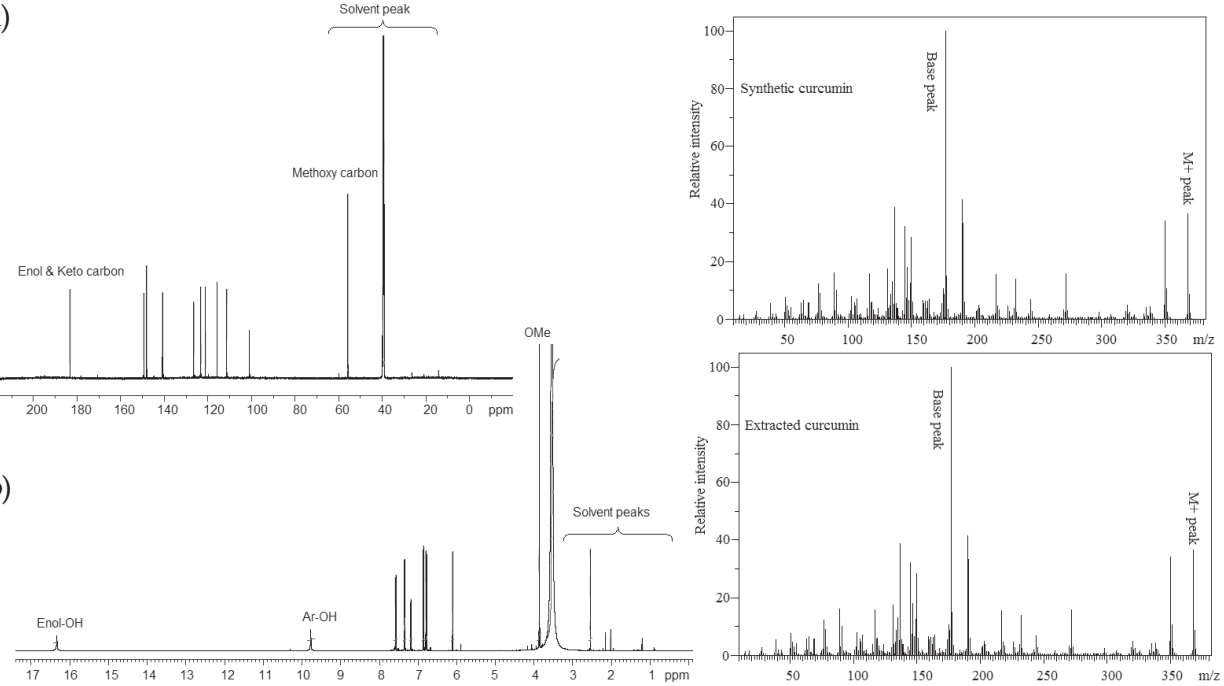

b)

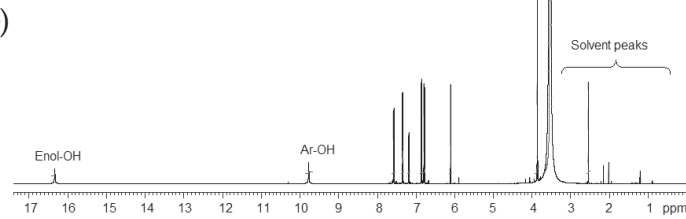

Fig. 3. Mass spectra and: a) ${ }^{13} \mathrm{C}$ NMR, b) ${ }^{1} \mathrm{H}$ NMR of curcumin in DMSO- $d_{6}$.

at $\delta 9.73$ ppm indicated the hydroxyl group, while in ${ }^{13} \mathrm{C}$ NMR $\delta$ at $55.8 \mathrm{ppm}$ corresponded to the methoxy group (Fig. 3). A broad singlet at $16.41 \mathrm{ppm}$ corresponded to the enolic hydroxyl proton. This enolic proton was equally shared by two O-atoms of the keto-enolic

Table IV. ${ }^{1} \mathrm{H} N M R$ and ${ }^{13} \mathrm{C} N M R$ spectral data $(\delta$, ppm) of curcumin

\begin{tabular}{llllllll}
\hline & \multicolumn{3}{c}{ Synthetic curcumin } & \multicolumn{3}{c}{ Extracted curcumin } \\
\hline & ${ }^{1} \mathrm{H}$ NMR & \multicolumn{2}{c}{${ }^{13} \mathrm{C}$ NMR } & & ${ }^{1} \mathrm{H}$ NMR & \multicolumn{2}{c}{${ }^{13} \mathrm{C}$ NMR } \\
\hline $\mathrm{H}$ & Integrals & $\mathrm{C}$ & Integrals & $\mathrm{H}$ & Integrals & $\mathrm{C}$ & Integrals \\
\hline 1 & $6.07(\mathrm{~s}, 1 \mathrm{H})$ & 1 & 101.0 & 1 & $5.98(\mathrm{~s}, 1 \mathrm{H})$ & 1 & 100.9 \\
$2-\mathrm{OH}$ & $16.41(\mathrm{~d}, 1 \mathrm{H})$ & $2,2^{\prime}$ & 183.4 & $2-\mathrm{OH}$ & $16.41(\mathrm{~d}, 1 \mathrm{H})$ & $2,2^{\prime}$ & 183.4 \\
$3,3^{\prime}$ & $6.75\left(\mathrm{~d}, 2 \mathrm{H}, J=16^{\mathrm{a}}\right)$ & $3,3^{\prime}$ & 121.2 & $3,3^{\prime}$ & $6.73(\mathrm{~d}, 2 \mathrm{H}, J=16)$ & $3,3^{\prime}$ & 121.1 \\
$4,4^{\prime}$ & $7.54(\mathrm{~d}, 2 \mathrm{H}, J=16)$ & $4,4^{\prime}$ & 140.9 & $4,4^{\prime}$ & $7.53(\mathrm{~d}, 2 \mathrm{H}, J=16)$ & $4,4^{\prime}$ & 140.7 \\
$5,5^{\prime}$ & - & $5,5^{\prime}$ & 126.5 & $5,5^{\prime}$ & - & $5,5^{\prime}$ & 126.4 \\
$6,6^{\prime}$ & $7.31(\mathrm{~d}, J=2)$ & $6,6^{\prime}$ & 111.3 & $6,6^{\prime}$ & $7.32(\mathrm{~d}, J=2)$ & $6,6^{\prime}$ & 111.4 \\
$7,7^{\prime}$ & - & $7,7^{\prime}$ & 148.1 & $7,7^{\prime}$ & - & $7,7^{\prime}$ & 148.0 \\
$8,8^{\prime}-\mathrm{OH}$ & $9.73(\mathrm{~s})$ & $8,8^{\prime}$ & 149.4 & $8,8^{\prime}-\mathrm{OH}$ & $9.74(\mathrm{~s})$ & $8,8^{\prime}$ & 149.4 \\
$9,9^{\prime}$ & $6.85(\mathrm{~d}, J=8.1)$ & $9,9^{\prime}$ & 115.8 & $9,9^{\prime}$ & $6.85(\mathrm{~d}, J=8.1)$ & $9,9^{\prime}$ & 115.7 \\
$10,10^{\prime}$ & $7.15(\mathrm{dd}, J=2,8.1)$ & $10,10^{\prime}$ & 123.3 & $10,10^{\prime}$ & $7.16(\mathrm{dd}, J=2,8.1)$ & $10,10^{\prime}$ & 123.2 \\
$\mathrm{OMe}$ & $3.83(\mathrm{~s}, 3 \mathrm{H})$ & $\mathrm{OMe}$ & 55.8 & $\mathrm{OMe}$ & $3.84(3 \mathrm{H}, \mathrm{s})$ & $\mathrm{OMe}$ & 55.7 \\
\hline
\end{tabular}

${ }^{a} J$ contants are given in $\mathrm{Hz}$ 

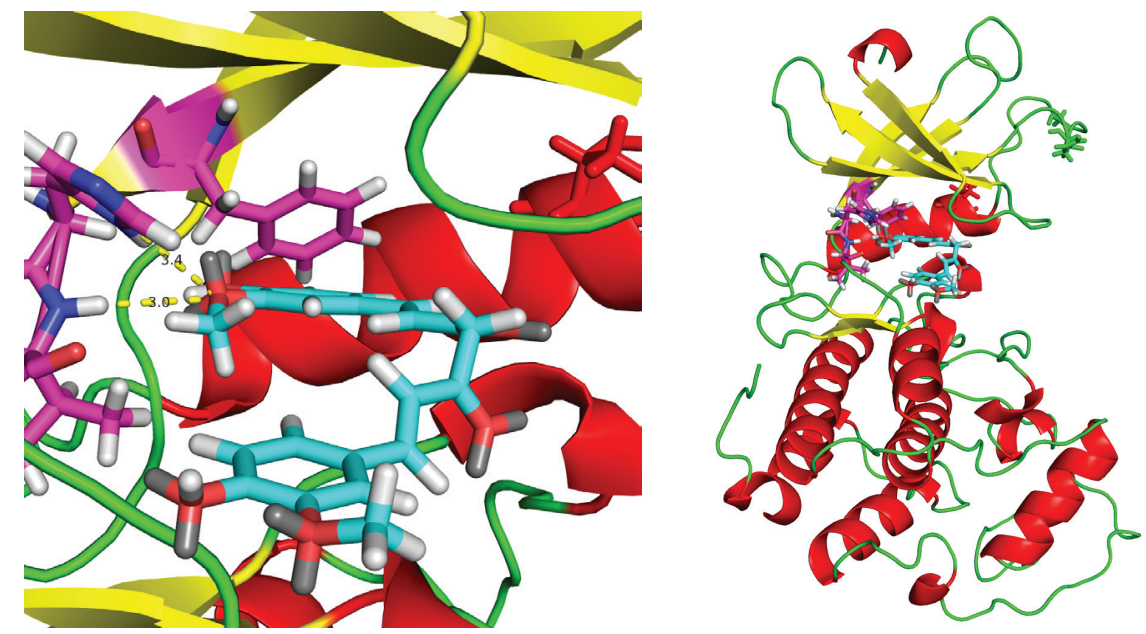

Fig. 4. Molecular docking of curcumin with CDK4 in an active state.

structure and was strongly deshielded due to involvement in the H-bond. Enolic and keto carbons are undistinguishable and equivalent, showing the $\delta$ value at $183.4 \mathrm{ppm}$ in ${ }^{13} \mathrm{C}$ NMR. Two double bonds and aromatic rings are completely equivalent. Thus, NMR studies further provided justification that the enolic form is the more stable and prominent form of curcumin. The extracted curcumin had the same purity level, but a time consuming procedure is required to get a reasonable yield, because curcuminoids are precipitated first and then curcumin is separated from the mixture. Hence, from the economical point of view, synthetic curcumin is more feasible than extracted curcumin with an excellent yield (89\%) and purity (99.8\%).

\section{Docking with cyclin dependent kinase}

Curcumin was docked in the CDK2 and CDK4 and CDK6 X-ray structures using the GOLD software with all its parameters set to default. It was observed that curcumin did not dock well at the binding site of ATP in CDK2, CDK4 and CDK6 because a typical kinase inhibitor-binding pose was absent. The docking pose of curcumin in CDK4 is shown in Fig. 4. This pose shows two weak polar interactions between the carbonyl group of the curcumin and the backbone NH of Val96 and the delta nitrogen of imidazole side chain in His95. The present study shows that curcumin does not inhibit the CDK pathway in cancer and may target cancer growth via some other pathways. Based on these docking studies, it may be suggested that there is a need to design new curcumin derivatives with better potency and specificity for CDKs.

\section{CONCLUSIONS}

A rapid and concise method for the synthesis of curcumin with excellent yield (89\%) and purity (99.8 \%) was developed. The extracted curcumin had the same purity level. 
However, to get a workable yield, a time consuming procedure is required to separate curcumin from the curcuminoid mixture. Thus, from the economical point of view, synthetic curcumin is more feasible than the extracted one.

Although there is a weak interaction between curcumin and a potential cancer target CDK4, the docking studies carried out in the present work suggest that it may not directly inhibit the CDK pathways but can control cancer by targeting other pathways. It may be suggested that there is a need to design new curcumin derivatives with better potency and specificity for CDKs.

\section{REFERENCES}

1. C. Ireson, S. Orr, D. J. Jones, R. Verschoyle, C.-K. Lim, J.-L. Luo, L. Howells, S. Plummer, R. Jukes and M. Williams, Characterization of metabolites of the chemopreventive agent curcumin in human and rat hepatocytes and in the rat in vivo, and evaluation of their ability to inhibit phorbol ester-induced prostaglandin E2 production, Cancer Res. 61 (2001) 1058-1064.

2. T. N. Almanaa, M. E. Geusz and R. J. Jamasbi, Effects of curcumin on stem-like cells in human esophageal squamous carcinoma cell lines, BMC Complement. Altern. Med. 12 (2012) 1-15 DOI: 10.1186/1472-6882-12-195.

3. B. B. Aggarwal, S. C. Gupta and B. Sung, Curcumin: an orally bioavailable blocker of TNF and other pro-inflammatory biomarkers, Br. J. Pharmacol. 169 (2013) 1672-1692; DOI: 10.1111/bph.12131.

4. A. B. Kunnumakkara, P. Anand and B. B. Aggarwal, Curcumin inhibits proliferation, invasion, angiogenesis and metastasis of different cancers through interaction with multiple cell signaling proteins, Cancer Lett. 269 (2008) 199-225; DOI: 10.1016/j.canlet.2008.03.009.

5. T.-F. Jiang, Y.-J. Zhang, H.-Y. Zhou, H.-M. Wang, L.-P. Tian, J. Liu, J.-Q. Ding and S.-D. Chen, Curcumin ameliorates the neurodegenerative pathology in A53T $\alpha$-synuclein cell model of Parkinson's disease through the downregulation of mTOR/p70S6K signaling and the recovery of macroautophagy, J. Neuroimmune Pharmacol. 8 (2013) 356-369; DOI: 10.1007/s11481-012-9431-7.

6. C. N. Conteas, A. M. Panossian, T. T. Tran and H. M. Singh, Treatment of HIV-associated diarrhea with curcumin, Dig. Dis. Sci. 54 (2009) 2188-2191; DOI: 10.1007/s10620-008-0597-z.

7. L. X. Na, Y. Li, H. Z. Pan, X. L. Zhou, D. J. Sun, M. Meng, X. X. Li and C. H. Sun, Curcuminoids exert glucose-lowering effect in type 2 diabetes by decreasing serum free fatty acids: a doubleblind, placebo-controlled trial, Mol. Nutr. Food Res. 57 (2013) 1569-1577; DOI: 10.1002/mnfr.201200131.

8. M. Garcia-Alloza, L. Borrelli, A. Rozkalne, B. Hyman and B. Bacskai, Curcumin labels amyloid pathology in vivo, disrupts existing plaques, and partially restores distorted neurites in an $\mathrm{Al}-$ zheimer mouse model, J. Neurochem. 102 (2007) 1095-1104; DOI: 10.1111/j.1471-4159.2007.04613.x.

9. S. Shishodia, T. Singh and M. M. Chaturvedi, Modulation of Transcription Factors by curcumin, in The Molecular Targets and Therapeutic Uses of Curcumin in Health and Disease (Eds. B. B. Aggarwal, Y.-J. Surh and S. Shishodia) (Series: Advances in Experimental Medicine and Biology, Vol. 595), Springer, New York 2007, pp. 27-148.

10. N. Handler, W. Jaeger, H. Puschacher, K. Leisser and T. Erker, Synthesis of novel curcumin analogues and their evaluation as selective cyclooxygenase-1 (COX-1) inhibitors, Chem. Pharm. Bull. 55 (2007) 64-71; DOI: 10.1248/cpb.55.64.

11. Y. Bustanji, M. O. Taha, I. M. Almasri, M. A. Al-Ghussein, M. K. Mohammad and H. S. Alkhatib, Inhibition of glycogen synthase kinase by curcumin: Investigation by simulated molecular docking and subsequent in vitro/in vivo evaluation, J. Enzyme Inhib. Med. Chem. 24 (2009) 771-778; DOI: $10.1080 / 14756360802364377$. 
12. K. E. Sheppard and G. A. McArthur, The cell-cycle regulator CDK4: an emerging therapeutic target in melanoma, Clin. Cancer Res. 19 (2013) 5320-5328; DOI: 10.1158/1078-0432.CCR-13-0259.

13. Hypercube Inc, HyperChem(TM) Professional 8.014 Hypercube, Gainesville (FL) 2008.

14. G. Jones, P. Willett, R.C. Glen, A.R. Leach and R. Taylor, Development and validation of a genetic algorithm for flexible docking, J. Mol. Biol. 267 (1997) 727-748; DOI: 10.1006/jmbi.1996.0897.

15. S. Kawano, Y. Inohana, Y. Hashi and J.-M. Lin, Analysis of keto-enol tautomers of curcumin by liquid chromatography/mass spectrometry, Chin. Chem. Lett. 24 (2013) 685-687; DOI: 10.1016/j. cclet.2013.05.006. 